\section{LA FORMA EN ACTO: MORFOGÉNESIS Y CIENCIAS DE LO VIVIENTE EN PAUL VALÉRY}

\author{
Laurence Dahan-Gaida \\ Université de Franche-Comté \\ ORCID iD: https://orcid.org/0000-0002-5747-1044 \\ laurence.gaida@univ-fcomte.fr
}

Cómo citar este artículo/Citation: Dahan-Gaida, L. (2018). La forma en acto: morfogénesis y ciencias de lo viviente en Paul Valéry. Arbor, 194 (790): a479. https://doi.org/10.3989/ arbor.2018.790n4004

Recibido: 25 marzo 2015. Aceptado: 25 agosto 2017.

RESUMEN: En esta contribución se exploran las relaciones entre estética y biología en dos textos de Paul Valéry: La introducción al método de Leonardo da Vinci (1894) y El hombre y la concha (1937). En estos ensayos, Valéry desarrolla una teoría morfogenética que atribuye al arte la función de reapropiarse de las fuerzas formativas que obran en la naturaleza con el fin de producir a su vez la misma variedad de formas, y restaura de este modo el lazo entre estética y ciencias de lo viviente que Goethe había sido el primero en establecer. La morfogenética valeryana es esencialmente dinámica, pues otorga privilegio al devenir de la forma, al movimiento de la producción que desembocará en la forma acabada. Pero ni la física ni la biología de esa época disponían de principios explicativos capaces de dar cuenta a la vez de la espontaneidad y de la organización de los procesos morfogenéticos en la naturaleza. Como se tratará de mostrar, los obstáculos epistemólogicos detectados por Valéry le llevarán a esbozar una morfología dinámica que anticipa las teorías de la complejidad desarrolladas a partir de los años 80 .

PALABRAS CLAVE: Valéry; Goethe; forma; morfogénesis; biología; emergencia; auto-organización; autopoiesis; complejidad.

\section{FORM IN ACTION: MORPHOGENESIS AND LIFE SCIENCES IN PAUL VALÉRY}

Copyright: (C) 2018 CSIC. Este es un artículo de acceso abierto distribuido bajo los términos de la licencia de uso y distribución Creative Commons Reconocimiento 4.0 Internacional (CC BY 4.0).
ABSTRACT: This contribution explores the relationship between esthetics and biology in two texts by Paul Valéry: Introduction to the Method of Leonardo da Vinci (1894) and Man and the Shell (1937). In these essays, Valéry develops a morphogenetic theory that assigns art the function of reappropriating the formative forces at work in nature, in order to produce, in turn, the same variety of forms. He thus reinstates the link between esthetics and life sciences that Goethe had been the first to establish. Valery's morphogenetics is essentially dynamic, privileging the form's process of becoming, and the movement of production which results in a finished form. However, neither the physics nor the biology of his period were endowed with explanatory principles capable of accounting for both the spontaneity and the organization of morphogenetic processes in nature. As this article shows, the epistemological obstacles identified by Valéry would lead him to sketch a theory of dynamic morphology that anticipated the theories of complexity developed since the end of the 1980s.

KEYWORDS: Valéry; Goethe; form; morphogenesis; biology; emergence; auto-organization; autopoiesis; complexity. 


\section{LA MORFOGÉNESIS DE GOETHE}

Si existen dos disciplinas emparentadas durante generaciones por sus métodos estas son la historia del arte y la biología, que comparten la misma precisión morfológica en la descripción y la misma exigencia de dominio de cantidades inconmensurables de objetos. En el siglo XIX, las teorías goetheanas sobre la emergencia de las formas naturales interesarán tanto a los científicos como a los escritores, contribuyendo así a establecer vínculos entre la dinámica de la forma y el discurso de la biología.

La práctica de Goethe es ante todo práctica de las ciencias de lo viviente, práctica de la anatomía y de la botánica, y también de la fisiología, ciencias que Goethe buscaba articular en un todo coherente al que significativamente denominaba "morfología", por la cual entendía una teoría de la forma, de la formación y de la transformación de los cuerpos orgánicos. La morfología se sitúa dentro de la historia natural en cuanto estudio de las formas y de las partes de la naturaleza organizadas en relación con el conjunto de lo viviente. Aunque Goethe explota la explicación legal matematizable para verificar la descripción sensible, a menudo estetizante, que permite ver la esencia misma de las cosas, la esencia goetheana no es exactamente una estructura, sino un poder de estructuración: es Bildung (la forma como actividad de formación) y no únicamente Gestalt (la forma fija). Además, la forma y la formación que definen a lo viviente son también y sobre todo con-formación, es decir interconexión e interacción con el medio de vida. El autor capta ese poder de conformación de la esencia mediante el concepto científico y filosófico de metamorfosis, el cual permite comprender "la dinámica de implicación de la ley en la concreción empírica” (van Eynde, 2011).

Goethe pretende ser por tanto el teórico de las formas que se transforman, se diversifican, aun conservando una identidad arquetípica. Por ello no separa el concepto de forma fenomenal (Gestalt) del de formación (Bildung), de fuerza formadora (Bildende Kraft), de pulsión (Trieb) y de estructura en el sentido de las relaciones entre el Todo y las Partes (relaciones mereológicas) (Petitot, 2003, p. 14). En este último punto es donde confluyen los sistemas del arte y de la naturaleza: en la idea de un todo que une las partes, de una totalidad orgánica capaz de traducir la coherencia subterránea de lo vivo tras la inagotable diversidad de las formas que la vida segrega. Goethe se verá entonces obligado a concebir "una estética morfológica [...] y una teoría morfológica de la cultura" (Cohn, 1999, p. 11) que amplíen el concepto de naturaleza, con el fin de poder incorporar a este el mundo de la organización y de las formas: así, "las ciencias naturales y la estética van de la mano, el proceso de la naturaleza, así como el de las artes, es una formación, una construcción de la forma que, por medio de procesos cognitivos, permite acceder a la esfera del sentido" (Cohn, 1999, p. 37).

Dado que su interés consistió en discernir la formación y la transformación de las formas, Goethe tenía una justificación para recurrir a la estética concebida como una ciencia general de la sensibilidad, pero también como un estudio sobre nuestra recepción de las "bellas formas" producidas por el arte (Class, 2011, p. 37). El poeta y pensador germánico sostenía, en efecto, que la forma artística deriva de la forma viviente, cuyas características esenciales reproduce, y que por ende puede, a cambio, facilitar la comprensión de esta, al menos en un plano heurístico. La forma deviene así la clave del entendimiento de todas las cosas, puesto que une informaciones objetivas y sensibles, pero también propiedades de virtualidades ocultas que dan acceso a la inteligibilidad (Wunenburger, 2011).

\section{LA MORFOLOGÍA DINÁMICA DE PAUL VALÉRY}

La hipótesis de un generativismo que opera tanto en las variaciones morfogenéticas de la naturaleza como en las imágenes creadas por el hombre ha sido retomada por numerosos filósofos y artistas del siglo $X X$, los cuales presienten la existencia en la naturaleza de una fuerza que dota de forma y que pluraliza en todos los niveles de su organización la red de sus figuras posibles. Se trata de una de las ideas directrices de Paul Valéry, quien se interesó por las transformaciones y modulaciones de la naturaleza viviente, y elaboró a partir de ellas el modelo de una "morfología generalizada".

El proyecto de Valéry remite a una tendencia de la modernidad que consiste en alinear la creación con el modelo de lo viviente, con la dinámica de su crecimiento. Algunos apuntes antiguos dan cuenta de su fascinación por los "ritmos primitivos", que alimentan en él la utopía de remontarse al origen, la de "la misteriosa unión entre la obra de arte y la naturaleza" (citado en Jallat, 1982). En efecto, el estudio de lo viviente permite considerar "la formación sistemática de las formas, la búsqueda de transformaciones, modulaciones, etc." que actúan como un poder de estructuración, o mejor dicho de formación (Robinson-Valéry, 1974, p. 342). Ahora bien, lo que interesa a Valéry tanto en el arte como en la naturaleza es precisamente la actividad de 
conformación: la Bildung antes que la Gestalt (la forma fija), lo posible antes que lo dado. No el producto acabado sino la producción de formas, la dinámica de generación tal como aparece en su encarnación por excelencia en la naturaleza, en la que Valéry ve una potencia de transformación combinada con otra de conservación y de regeneración. La teoría valeriana de la forma está fundada sobre esa intuición profunda de que la forma es un desarrollo inmovilizado, la fijación de una inestabilidad fundamental que hace que todo ser viviente sea constantemente él mismo y constantemente otro. Goethe no decía otra cosa al describir la arquitectura como "música inmovilizada".

Esa concepción dinámica de la forma, que valora el proceso en la creación, trae como consecuencia la emancipación del arte respecto de la mimesis en el sentido de 'copia', y la sustitución de esta por una poiética que subraya la producción antes que el producto creado. Desde tal óptica, el arte ya no es un proceso secundario, relegado a una imitación laboriosa de la naturaleza, sino el efluente mismo de su actividad creadora. Se anula así toda relación jerárquica entre arte y naturaleza, techné y physis: "El arte como imitación de la naturaleza -esta simpleza es cierta si uno recuerda que imitar puede ser mejor que copiarsignificaría desentrañar los procedimientos y someterlos -como en las máquinas- y no querer producir el exterior -cualquier cosa que se muestra-. Pero el verdadero arte es poseer todo el conjunto -los medios libres de transformación-" (Celeyrette-Pietri, 1987, vol. III, p. 293). La función del arte no es imitar la naturaleza, en el sentido de la natura naturata, sino de la natura naturans. Dicho de otro modo: reapropiarse de las "fuerzas formativas" que operan en ella con el fin de producir a su vez la misma variedad de formas: "Naturaleza, es decir: la Producente o la Productora. A ella es a quien le encargamos producir todo aquello que no sabemos hacer y que, sin embargo, nos parece hecho" (Hytier, 1957, p. 897) ${ }^{1}$. Se explica entonces su fascinación por la concha, que constituye a sus ojos la forma por excelencia, puesto que muestra el trabajo de las fuerzas de la naturaleza: es la forma hecha visible de las fuerzas naturales. Valéry le dedicará en 1937 un célebre ensayo: El hombre y la concha.

\section{El hombre y la concha}

Para Valéry, lo fascinante de la concha -y de otras formas de prominente morfología como el cristal, la flor, etc.- es que se trata de objetos complejos que resultan "más inteligibles a la vista, aunque más misteriosos para la reflexión, que todos los demás que vemos indistintamente" (Hytier, 1957, p. 887)2. La concha pone en juego una disyunción entre la inteligibilidad inmediata e intuitiva producida por la percepción sensible de la forma y el misterio intelectual sobre el que reposa su principio organizador interno. El conflicto epistemológico se sitúa en la oposición entre una construcción mecánica causal (regida por tanto por la física clásica) y una producción viviente final (teleológica):

Concebimos la construcción de esos objetos; y por ello nos interesan y nos retienen; no concebimos su formación, y por ello nos intrigan. A pesar de estar nosotros mismos hechos o formados por conducto de crecimiento insensible, no sabemos crear nada por ese conducto (Hytier, 1957, p. 887) ${ }^{3}$.

Para Valéry, las "formas naturales son leyes que hablan a nuestros ojos" (Hytier, 1957, p. 1173): su poder legislador se da a través de una experiencia sensorial que es ante todo de tipo visual. Ahora bien, las formas como la concha oponen resistencia al conocimiento, puesto que su proceso generador no se deja aprehender: "Encontramos en su apariencia la semejanza de una intención y de una acción que les hubiera dado forma similar a lo que los hombres saben hacer, y pese a ello la evidencia de procedimientos que nos resultan prohibidos e impenetrables" (Hytier, 1957, p. 887) ${ }^{4}$. El problema que plantea la concha es el de la finalidad de la organización: la concha es una forma organizada, una estructura, una totalidad, pero resulta imposible desvelar el esquematismo de su composición (Petitot, 2003 , p. 120). En ese sentido, es la imagen de la vida misma, que uno no puede "representar ni como algo necesario a partir de las cosas no vivas, ni como algo del todo accidental; que parece fabricar fines y no tenerlos; significar o aspirar a cierta tendencia a la desigualdad e igualarse en estadísticas" (Robinson-Valéry, 1974, p. 767).

Con el fin de "reducir" la complejidad de la concha como forma, Valéry probará diversos enfoques, empezando por el geométrico. Pero este revela muy rápidamente sus limitaciones: solo consigue describir la figura general de la concha sin poder explicar la dinámica de su engendramiento:

Hélices, espiras, evoluciones de relaciones angulares en el espacio, el observador que las considera y se esfuerza por traducirlas en sus formas de expresión y de comprensión no deja de percibir un carácter esencial de las formas de ese tipo. Una concha, como una mano, como una oreja, no puede confundirse con una concha simétrica. Si dibujamos dos espirales, una de 
las cuales sea la imagen de la otra en el espejo, ningún desplazamiento de esas curvas gemelas en su plano las llevaría a superponerse (Hytier, 1957, p. 889) ${ }^{5}$.

La forma de la concha indica el funcionamiento del torbellino del que nace: "Ese movimiento de torsión lo encontramos formalmente en la concha. Una extraña dialéctica une aquí el interior y el exterior. El molusco que vive en la concha excreta, expulsa fuera de sí, pero también atrae, absorbe. Rechazo hacia el exterior e integración: movimiento centrífugo y centrípeto" (Hytier, 1957, p. 889). Al manifestar las "fuerzas formativas" que la originan, la figura de la concha, al igual que la del torbellino, se relaciona con la figura hiperonímica de la espiral, que prefigura el organismo con su propia economía interna. Imagen de la vida desplegándose, la figura del torbellino pone de manifiesto la sensibilidad de Valéry respecto a la dinámica de las cosas por venir, pero es también la imagen de una fuerza mortífera que lo arrastra todo con su movimiento aspirador, engullidor (Pietra, 1981, p. 43).

Al fin y al cabo, el geómetra, con su arsenal de figuras y de operaciones, no puede extraer sino tres observaciones simples de su examen de las conchas: podrá describir su figura general, señalar bruscas e imprevisibles interrupciones en el aspecto de las formas $y$, por último, constatar una superioridad estadística de las diestras sobre las siniestras en el enroscamiento de las espirales. La concha obliga a una aprehensión semelfactiva (válida para una sola ocasión) ante la cual la geometría pura se muestra incompetente, puesto que, como toda forma viva, consta de una tendencia a escapar a la nivelación de la repetición para mantener una asimetría: "Todas las conchas cuya forma deriva del enrollamiento de un tubo manifiestan necesariamente esa disimetría, a la que Pasteur concedía tanta importancia y de la que obtuvo la idea maestra de las investigaciones que lo llevaron del estudio de ciertos cristales al de las fermentaciones y al de sus agentes vivos" (Hytier, 1957, p. 889) ${ }^{6}$. Si en cuanto forma la concha escapa a nuestro entendimiento, es debido a "la presencia misma de lo que caracteriza la vida: la no-simetría. ¡Derecha e izquierda no son intercambiables, la permuta acabaría con su especificidad!" (Hytier, 1957, p. 889).

Puesto que la geometría no consigue dar cuenta de las fuerzas de formación que operan en la concha, una segunda tentativa consistirá en rehacer su forma mediante el pensamiento, como si se tratara de una obra humana. Porque la mente, constata Valéry, está "rigurosamente limitada, en su representación de las cosas, por la consciencia que tiene de sus medios de acción exterior, y por el modo en que esa acción procede de ella, sin tener necesidad de conocer el mecanismo": "solo sé lo que sé hacer" (Hytier, 1957, p. 889) 7 . Para Valéry, el concepto de "hacer" es anterior e indisociable del "saber": "'Explicar' no es otra cosa que describir una manera de hacer: no es otra cosa que rehacer mediante el pensamiento" (Hytier, 1957, p. 891) ${ }^{8}$. Pero las limitaciones del "poder" y del "hacer" son estrechas, y las alcanzamos en cuanto nos enfrentamos a las formas más complejas de la naturaleza, que ponen en juego no ya una serie de fuerzas de construcción sino de formación (Coquet, 2006, p. 15):

Pienso en la naturaleza viva al observar cómo hace -ino!- cómo suceden en ella formaciones y transformaciones totalmente ajenas a nuestros modos de hacer y de modificar -y que resultan inexpresables por medio de los términos que poseemos, que son actos de percepción o de ejecución-.

Sin embargo, el hacer (el nombre general de esos fenómenos) es una creación particular de la naturaleza viviente que se detecta en ciertas bestias (entre las cuales nos encontramos nosotros) -pero no en las plantas ni en la mayoría de los animales-.

Hacer $=$ dar forma.

El león no le da forma a nada. A no ser, claro, que le dé forma de comida a un antílope vivo, que con sus dientes haga de su carne una masa absorbible.

-No es acaso, dice el León, una Obra "de arte" formidable, "la que" hago con mis mandíbulas- cuando al transformar la vida del Otro en muerte, y su muerte en mi vida, mi enorme rostro, mi máscara de oro de espléndidos dientes se ocupa con esmero de la presa abatida? (Robinson-Valéry, 1974, p. 763).

Comprendemos rápidamente que la generación de la concha obedece a leyes muy distintas que las de los actos humanos, que responden a un designio, a una idea que coordina y organiza. Ahora bien, si "nuestros designios conscientes y nuestras construcciones o fabricaciones voluntarias parecen del todo ajenas a nuestra actividad orgánica profunda", los de la araña o el molusco traducen por el contrario una verdadera “inherencia orgánica” (Robinson-Valéry, 1974, p. 896).

Una vez constatadas las limitaciones del "hacer", Valéry llevará a cabo una última tentativa para acercarse al misterio de la concha, refiriéndose esta vez a la ciencia y a su modelo de explicación causalista. Pero el modo de conocimiento científico resulta tan inadecuado como los demás métodos al obligarnos a reconocer que "nuestro conocimiento de las cosas de 
la vida es insignificante comparado con el que tenemos del mundo inorgánico" (Hytier, 1957, p. 900) ${ }^{9}$. La concha, en cuanto forma natural, no puede ser reducida por ninguno de los medios de nuestra ciencia:

$\mathrm{Ni}$ máquina, ni intención, ni azar... todos nuestros medios están excluidos. Máquina y azar son los dos métodos de nuestra física; en cuanto a la intención, no puede intervenir sin que el hombre mismo esté implicado, explícitamente o en forma encubierta (Hytier, 1957, p. 900) ${ }^{10}$.

En una anotación de los Cuadernos de 1931, Valéry detalla por qué los conceptos de finalidad, de causa y de efecto son inadecuados para dar cuenta del crecimiento de la forma:

La naturaleza viviente sabe cuán necesarias son la física y la química para la construcción de sus especies. Ignoro si le importará la astronomía. - Está claro que para ella la cantidad y la calidad no se distinguen de la misma manera que para nosotros, tampoco la materia y la energía, ni el tiempo y el espacio etc. Opera transformaciones extraordinarias - El mismo problema resuelto por ella y por nosotros ofrece dos métodos muy distintos - Nosotros actuamos, y nuestras acciones nos imponen la idea de finalidad, de causa, de efectos - Pero esos conceptos invencibles no proceden en el caso de la naturaleza viviente y nos sitúan ante dificultades insalvables cuando se los aplicamos. Conseguimos pensar que aquello que ignora sabe, que aquello que no piensa prevé - etc. [...] Solo disponemos del acto como tipo inteligible. Pero el acto no es otra cosa que un caso muy limitado y particular de la naturaleza viviente (Robinson-Valéry, 1974, p. 751).

El estudio de los seres vivos, vegetales o animales, demuestra la imposibilidad de reducir la naturaleza viviente a las leyes de la física clásica, cuyos conceptos operativos hace fracasar: fuerza, causalidad, movimiento, determinismo, etc. Por lo tanto, habrá que dirigir la mirada hacia otro tipo de ciencia donde "el hacer es mínimo, donde la capacidad de producir o reproducir los fenómenos está muy restringida" (Robinson-Valéry, 1974, p. 906). Es lo que provocará que Valéry se aleje de la física -durante mucho tiempo su paradigma de referencia- para buscar en la biología un modelo de inteligibilidad operatorio con el que fundar su teoría morfogenética (Coquet, 2006). Pero la biología resultará igualmente decepcionante -dado que el análisis microscópico no basta para satisfacer la curiosidad del observador-, tanto como la toma en consideración de los constituyentes que las ciencias de lo viviente nos han enseñado a diferenciar: "las fuerzas, el tiempo, la materia, las relaciones, y los diferentes 'órdenes de tamaño' entre los cuales nuestros sentidos nos imponen distinguir. La vida pasa una y otra vez de la molécula a la micela, y de esta a las masas sensibles, sin tomar en cuenta los compartimentos de nuestras ciencias, es decir de nuestros medios de acción" (Hytier, 1957, p. 903) ${ }^{11}$.

Para comprender las morfologías, concluye Valéry, necesitaríamos una nueva ciencia de lo viviente que, a imagen de esta última, "no separ[e] la geometría de su física y confí[e] a cada especie aquello que necesita de 'invariantes' más o menos 'diferenciales' para conservar un acuerdo satisfactorio en cada individuo, entre lo que es y lo que hay" (Hytier, 1957, p. 903) (12. $^{12}$

\section{EPISTEMOLOGÍA DE LO VIVIENTE}

En cuanto forma natural, la concha propicia el fracaso tanto de la física clásica -la de Laplace y Lagrange- como de la biología contemporánea de Valéry ${ }^{13}$. En los Cuadernos, Valéry insiste repetidamente en las carencias de las ciencias de su tiempo a la hora de dar cuenta de la complejidad de las formas naturales. Así, en una anotación de 1921, apunta que:

La voluntad de considerar a los seres vivos sirviéndose exclusivamente de la fisicoquímica quizá sea tan vana como lo fue la de considerar la fisicoquímica sirviéndose exclusivamente de la mecánica de sólidos. Hay sin duda una parte de fisicoquímica, puesto que los seres vivos están en ese medio, beben de él y le devuelven lo que rechazan, sus fuerzas se ejercen sobre él, etc. -y quedan reducidos a cuerpos químicos y gas, pero puede haber algo más- y no es imposible que dispongan de leyes propias (Robinson-Valéry, 1974, p. 128).

Que las formas vivas parezcan obedecer a leyes propias significa que conjugan de manera totalmente singular un poder de auto-organización con una espontaneidad que semeja desafiar las leyes de la física. Como señala Valéry en una anotación de 1918: "La maravilla de la vida reside en la combinación de la espontaneidad aparente con la organización. En lo no-vivo hay una degradación o difusión que es lo espontáneo, lo natural, lo que es de esperar, lo probable" (RobinsonValéry, 1974, p. 104) $)^{14}$.

En otro pasaje de los Cuadernos Valéry se pregunta "cómo se ha formado un sistema de redención próxima, de contra-Carnot, en un medio donde la degradación es la regla [...] Ello nos lleva a buscar aquello que en la naturaleza -inorgánica- retrasa la degradación. Levantamientos - Retrasos locales" (Robinson-Valéry, 1974, p. 745). Al igual que en la cita anterior, Valéry 
se refiere aquí al segundo principio de la termodinámica, que establece la tendencia de la energía a la dispersión, a la difusión irreversible durante sus procesos de transformación espontánea. Esa tendencia de la naturaleza hacia el equilibrio, denominada ley de crecimiento de la entropía, fue interpretada por los físicos del siglo XIX como una "flecha del tiempo" orientada hacia el desorden y que condenaba los sistemas a una ineluctable muerte térmica. Al predecir el crecimiento del desorden en un mundo dominado por la uniformidad, la termodinámica clásica era incapaz de explicar el surgimiento de nuevos órdenes en la naturaleza. Ahora bien, la naturaleza no deja de inventar espontáneamente sistemas organizados muy complejos, capaces por sí mismos de mantener su propia organización y que, en el transcurso de la evolución, alcanzan grados de orden y complejidad cada vez más elevados. Parece desafiar de este modo la tendencia espontánea a la uniformidad y al equilibrio que le atribuye el segundo principio de la termodinámica. En el siglo XIX, la ciencia parecía disponer por tanto de dos secuencias temporales cuyas flechas eran opuestas: mientras que la termodinámica describía un proceso irreversible de pérdida de energía y de crecimiento del desorden, la biología describía una evolución hacia formas de organización cada vez más sofisticadas y diferenciadas. La contradicción entre Carnot y Darwin se hubiera dicho insalvable hasta que algunas teorías recientes permitieron reconciliar ambas flechas del tiempo, explicando la aparición espontánea de formas organizadas en la naturaleza por una mezcla de azar y determinismo.

Alain Boutot ha recogido cuatro teorías matemáticas pertinentes para explicar la emergencia de las formas naturales y las ha expuesto en su libro sobre $L a$ invención de las formas. En primer lugar, la teoría de las catástrofes, que proporciona modelos topológicos de aparición de discontinuidades en un medio continuo; la teoría de los fractales, que explora una familia de formas geométricas a la vez complejas e irregulares cuya particularidad principal es la auto-similitud; la teoría de las estructuras disipativas, que muestra cómo algunas organizaciones espontáneas, evolutivas, pueden emerger en el interior de un medio discreto atravesado por flujos de energía; y por último la teoría de los atractores extraños, que formaliza el comportamiento de procesos caóticos como las turbulencias.

Estas teorías tienen en común su interés por la realidad tal como nos viene dada a través de la serie infinita de sus formas y de sus metamorfosis. No buscan "purificar" la naturaleza despojándola de sus accidentes, sino que afrontan el desorden y la imprevisibilidad que perturban los equilibrios y favorecen la emergencia de nuevas organizaciones. Lejos de constituirse contra lo sensible, proponen una "fenomenología de lo aparente" que considera la naturaleza en su inmediatez, tal como se nos ofrece en el mundo de la percepción ordinaria. Como destaca Alain Boutot, "el universo de las teorías morfológicas no es el universo frío y sin sorpresas de Newton y Laplace, sino un mundo de formas diversas y cambiantes" (Boutot, 1993, p. 218). Esas formas son cambiantes porque están en contacto con el universo, el cosmos, que no es únicamente el "buen orden" de Platón, sino también el lugar del "aparecer de las formas, aparecer que debemos distinguir de la apariencia, del reflejo del eidos, de la Idea-Forma platónica" (Vercruysse, 2011, p. 303). El aparecer no obedece a una dinámica previsible, sino que es lo inesperado de la forma, una forma en acto, que solo existe en la medida en que traza el camino de su propia formación.

La misma tendencia se confirma en las ciencias de lo viviente, que insisten cada vez más en la inestabilidad como régimen de funcionamiento de los sistemas naturales. Reconocen que sus objetos "no son solo sistemas capaces de conservar/reproducir estructuras estables en condiciones inestables y de regular/programar sus operaciones. Son asimismo seres que muestran una variedad de formas y una creatividad morfológica que ha maravillado a los naturalistas de todas las épocas" (Fagot-Largeault, 1995, p. 289). Existe por tanto la posibilidad de considerar los problemas de morfogénesis desde un punto de vista a la vez más dinámico y más abierto al azar, como atestigua por ejemplo el desarrollo actual de una perspectiva embriológica que describe la invención de las formas como el resultado de la producción en los organismos de una multitud de posibilidades que son sometidas al mecanismo de la selección (Fagot-Largeault, 1995, p. 292).

\section{DE LA BIOLOGÍA A LA ESTÉTICA}

No cabe duda de que a Valéry le hubieran interesado enormemente esas teorías cuyo punto en común es explicar los procesos de morfogénesis mediante mecanismos que un crítico ha calificado ya no de "causales" sino de "geométricos" (Kellert, 1993, p. 104). Dichas teorías sustituyen las concepciones estáticas de la forma como estructura por un concepto genético de la forma como auto-organización emergente o como autopoiesis. Ofrecen entonces una respuesta al problema de Valéry, que anhelaba "una Dinámica y una Física de la Forma o, dicho de otro modo, una teo- 
ría de la (auto)-organización" (Petitot, 2003, p. 120), capaz de demostrar que la naturaleza "no separa su geometría de su física" en las formas que produce.

Por su parte, los científicos no se han equivocado al reconocer en Valéry a una suerte de precursor. Así, René Thom describe su sorpresa cuando descubrió "en la pluma de Valéry ideas, metáforas que juegan un papel importante en [su] propia 'teoría de las catástrofes'” (Thom, 1983, p. 193). Para sostener su aserción, Thom cita un largo fragmento de los Cuadernos en el que Valéry trata de describir la dinámica del crecimiento de las plantas haciendo hincapié en la discontinuidad del proceso:

Me gustaría ver una planta estudiada por un ingeniero experto en electricidad y química.

Doble empuje --

Planta, sistema de fuerzas. Cohete. [...]

Las plantas me recuerdan a esas leyes discontinuas que observo in natura rerum. Colores repentinamente variados; implantación de los ramos, la flor repentinamente roja. [...]

El árbol crece por empuje pero las fuerzas de crecimiento de superficie, de volumen, dependen de una suerte de esquema que regula la periodicidad de las emisiones de ramos, de pecíolos, de nervaduras - Las formas de las hojas dependen de él.

El esquema puede concebirse como un sistema de líneas de flujo y de super(ficies) equipotenciales -isobaras que representan las capas continuas, o tubos cerrados. Las magnitudes capilares reinan en el interior.

La semilla contiene lo necesario para iniciar una evolución, un funcionamiento, un 'tiempo' en un medio, cuya concentración cambia - Encierra un explosivo. [...]

La forma es, por una parte, el orden de los contactos y, por otra (en las formas naturales), el lugar de los puntos de discontinuidad de las leyes, siempre que ese lugar sea continuo. Esa estructura dinámica de las plantas - sugiere que nuestras ideas sobre la vida y la muerte se remontan a una época en la que no teníamos idea del funcionamiento - algo que las máquinas nos permiten observar. Los seres vivientes están basados en un ciclo, o más bien en un sistema de ciclos - y de epiciclos - del que no tienen sino una consciencia bastante tosca -- Es posible vincular en ocasiones esos ciclos a los ciclos astronómicos - y a ello viene a unirse la idea tosca del tiempo -- 'Orden del mundo'.
Pero el tiempo es exclusivo de cada sistema, incluso de cada funcionamiento, del cual no es otra cosa sino el nombre vago. / No hay tiempo no-funcional, nocíclico. [...] La planta muestra su tiempo-que es edad, que es masa y figura (Robinson-Valéry, 1974, p. 757).

Parece que Valéry atisbó una teoría dinámica universal cuya originalidad -y cuyo carácter premonitorio- reside en la puesta en evidencia de la aporía continuo/discontinuo que constituye la fuente de toda modelización natural: al describir la morfogénesis de las plantas, evoca en efecto una temporalidad discontinua que está marcada por la aparición de lugares de "catástrofe" en un medio altamente continuo ${ }^{15}$.

A semejanza de René Thom, llya Prigogine, el padre de la termodinámica no lineal y de la teoría de las estructuras disipativas, advirtió numerosas convergencias entre sus propios trabajos y las reflexiones de Valéry sobre el tiempo: en primer lugar, la idea de un devenir complejo que no obedece a leyes deterministas sino al concepto de lo "posible-en-cada-instante" (Hytier, 1957, p. 1467); igualmente el reconocimiento de una pluralidad de temporalidades distintas y la idea de procesos marcados por no-linealidades y bifurcaciones, esto es por puntos críticos donde la evolución de un sistema puede orientarse hacia direcciones imprevistas; por último, la reflexión sobre las transiciones del desorden al orden que van a contracorriente de la termodinámica clásica y de su interés exclusivo por el paso del orden al desorden, es decir por la entropía. En efecto, los Cuadernos están repletos de observaciones sobre la aporía generada por la oposición entre el tiempo termodinámico y el tiempo de lo viviente, que es un tiempo largo, creador, cuya flecha está orientada en sentido contrario a la entropía:

Un ser viviente es un sistema material que se conserva mediante transformaciones en sentido contrario al principio de Carnot -de modo que por cada trans(formación) espontánea que sufre, produce una trans(formación) artificial en sentido contrario (cuya E(nergía) U(tilizable) extrae de una trans(formación) espontánea del entorno) (Robinson-Valéry, 1974, p. 749).

En otra anotación, con fecha de 1935, Valéry relaciona directamente la neguentropía con la no-clausura que caracteriza los sistemas vivientes:

(Las propiedades de los sistemas vivientes) implican contravenciones a Carnot (consecuencias, de hecho, del no-aislamiento), contravenciones regulares y no accidentales, contravenciones organizadas, acaso sea la definición de la organización -del anti-desorden (que es del orden de lo improbable)- Pero limitadas (la muerte) (Robinson-Valéry, 1974, p. 761). 
Si Valéry sigue utilizando el vocabulario de la termodinámica es con el fin de establecer una clara distinción entre los sistemas cerrados de los que se ocupa la termodinámica clásica y los sistemas vivos que intercambian energía con su entorno y cuyo destino puede ser otro que la entropía. En una anotación de 1933 titulada Tiempo de planta, sugiere la existencia de un tiempo-forma al que se puede acceder mediante la aprehensión sensible de las plantas:

Nada impone mejor a la mente el problema de la Modulación -esa parte divina en las artes- que los empalmes de las formas vegetales y los que en seguida se encuentran en los organismos animales.

Pasar de un plano a otro, de un tono a otro, de un 'universo' a otro -esa sustitución, como del sueño a la vigilia y viceversa-, del día a la noche y viceversa -de lo libre a lo atado-.

En las extremidades de las plantas, las soldaduras, las diversas diferenciaciones a partir de un mismo rango o anillo o nivel-edad (puesto que la edad de una planta es una forma y una masa). Hay un momento de tiempo-planta en que el cambio de figuras se acentúa -especie de aceleración periódica morfogénica- crecimiento, figura y funciones están relacionadas [...] (Robinson-Valéry, 1974, pp. 755-756).

"Modulación" es la palabra clave de la estética valeryana, cuyo modelo toma prestado al mundo de lo vivo, como confirma la siguiente anotación de 1917: "La bella arquitectura se asemeja a la planta. Se ve en los detalles -en la modulación de las formas, que permite conducir un edificio de arriba abajo, como vegetalmente (para el ojo). / La ley de crecimiento tiene que ser sensible" (Robinson-Valéry, 1974, p. 937). Antes de convertirse en la teoría de los armónicos, la ley de modulación se presenta como una técnica "de sustitución por similitudes y armónicos" que permite generar continuidad en el encadenamiento de las formas:

Pasajes y modulaciones - El secreto mejor guardado del arte - y la marca del arte exquisito. / Aquel que ignora esto es una bestia - Aun poderosa... Ese secreto une el dedo o la mano que pasa a la forma de la luz-sombra. / La naturaleza viviente es invencible en esto. Sabe rematar un tallo, abrir un orificio, abrir la extremidad de un canal -alargar un órgano externo, intercalar un globo. / Transiciones. / Sin embargo, este problema es profundo - Porque no es otro que el de la combinación de la acción y la materia (en el sentido relativo de cosa que se conserva) o el de la oposición y la combinación de la construcción y la for- mación (vid. signif(icativo) y formal. Todavía (después de 44 años) no he esclarecido este asunto) (RobinsonValéry, 1974, pp. 1040-1041).

Es en la pintura de Leonardo da Vinci -elevado en los Cuadernos a la categoría de "ángel de la morfología"- donde Valéry observa la realización de esa técnica. Para Leonardo, pintar consiste en transformar cada singularidad en "fragmento de un indivisible psíquico", en el que "todo lo que aparece no lo hace sino en una suerte de resonancia de similitudes" (Celeyrette-Pietri, 1987, vol. V, p. 26) ${ }^{16}$. Esto le permite en sus cuadros pasar sin transición de las "curvaturas masivas a los ropajes multiplicados, del humo naciendo de los tejados a las lejanas arborescencias [...] de los peces a los pájaros; de las orejas y los rizos a los torbellinos petrificados de las conchas", y "de la concha a la voluta del tumor de las ondas" (Valéry, $1894 / 1964$, p. 35$)^{17}$. En ese glissando de imágenes lo determinante no es la semejanza figurativa, sino la ley de modulación que permite construir un campo de "posibilidades armónicas" donde "cada uno de los objetos de la vista está virtualmente cargado de reflejos de los objetos contiguos [...] Cada objeto de pensamiento, imaginado, engendra un campo de similitudes, como si un ojo con una sensibilidad inaudita viera sobre cada objeto la imagen de los objetos contiguos y pasara de uno a otro -ya no hay objeto aislado, es decir sin otros-" (Celeyrette-Pietri, 1987, vol. XXIX, pp. 350-351). De la imagen de la onda surge por tanto la de la concha, que no es en sí misma sino la forma hecha visible de fuerzas marinas, cuyo movimiento en espiral se repite en otros torbellinos -oreja, rizos, ondas, cabelleras, etc.--

Al actuar como "un molde variable continuo", la ley de modulación traduce el dinamismo común a las fuerzas formativas de la naturaleza y a las fuerzas energéticas que animan el espacio de la visión, uniendo en un todo coherente la biología, la estética y la cognición. Es ahí precisamente donde reside el genio de Leonardo a ojos de Valéry, en una inteligencia formal que le permite aunar percepciones sensibles y propiedades ocultas que dan acceso a la inteligibilidad. Leonardo consigue que la naturaleza sea inteligible y asimilable para el cerebro humano gracias a una "lógica especial de las imágenes" cuya característica propia es hacer visibles las estructuras que están fuera del alcance de nuestra percepción. Leonardo no busca tanto pintar árboles, peces o conchas, como hacer visible "[la] potencia siempre inminente [de la naturaleza]" (Valéry, 1894/1964, p. 34) ${ }^{18}$ cuyas fuerzas imprimen su rastro viviente en los seres y las 
cosas. No pinta formas sino fuerzas invisibles, el devenir de la forma, que es una virtualidad susceptible de actualizarse en los objetos más variados. Sin embargo, antes de operar sobre el lienzo, la continuidad se construye en el campo mental -en la imaginación o en el espacio dinámico de la visión-. A través de Leonardo, Valéry recupera la hipótesis goetheana del vínculo entre morfogénesis biológica y estructuras cognitivas, hipótesis que ha sido retomada en el siglo XX, concretamente por Alan Turing, para quien el proyecto de una teoría fisicalista unitaria de las formas biológicas y de las estructuras cognitivas está justificado por una aproximación a la forma desde un punto de vista genético, como auto-organización emergente.

La estrecha relación entre la organización biológica, la estructuración de la percepción y la estética remite en Valéry a un lugar donde las cosas "que están naciendo a la forma" ya no se encuentran "en" el espacio, sino que "hacen" su espacio, lo generan dinámicamente, "[en dicho espacio] la exterioridad se vuelve en cierto modo 'endógena'" (Chédin, 1982, p. 126). Encontramos esa idea, por ejemplo, en una anotación de los Cuadernos con fecha de 1926: "La imagen del árbol o de la planta en la que pienso tan a menudo es imagen representativa de leyes simples de la cosa viviente elemental y hace sensibles ciertas 'fuerzas', una continuidad, funciones de fuerzas, un vínculo variable vectorial, una geometría intrínseca de una sola pieza donde dimensiones, tiempo, masa, fuerzas están unidos y se manifiestan unos a través de otros" (Robinson-Valéry, 1974, p. 742). Consideradas desde el punto de vista de su nacimiento, las formas no solo configuran su espacio, sino que lo configuran temporalmente. Le dan un ritmo, en el sentido etimológico del término descubierto por Benveniste -"la forma en el instante en que es asumida por aquello que es moviente, móvil, fluido [...]. Es la forma improvisada, momentánea, modificable" (Benveniste, 1951/1966, p. 333)-, la forma de lo que no tiene consistencia orgánica y sin embargo crea de manera perpetua su modulación imprevisible, su respiración independiente del movimiento del metrónomo. Dicho de otro modo: la forma viviente, aprehendida en su imprevisible devenir, en su génesis, es la que debe ser reinscrita en el marco de una teoría general de la morfogénesis. En cuanto fenómeno de ritmo, la forma quizá no sea al fin y al cabo sino una "manera particular de fluir"; "'disposiciones' y 'configuraciones' sin fijeza ni necesidad natural, resultantes de un arreglo siempre sujeto a cambio" (Benveniste, 1951/1966, p. 333).

\section{CONCLUSIÓN}

Partiendo de las carencias detectadas en la biología de su tiempo, que se encontraba todavía envuelta en cuestiones metafísicas de las que la física había sabido deshacerse años atrás, Valéry fue capaz de formular las preguntas, de construir los problemas cuya solución no se encontró hasta cinco décadas después. Ello lo llevó a prefigurar algunas orientaciones que apenas habían sido esbozadas, en vida del autor, en las ciencias matemáticas, físicas y biológicas, permitiéndole así anticipar el paradigma morfológico que ha vuelto a hacer su aparición en las ciencias y las artes a finales del siglo XX. "Trabajo para alguien que vendrá después", escribió. Lo cual constituía, según él, una de las funciones más características del arte: "Las artes descansan sobre lo desconocido del pensamiento -sobre sus coincidencias por cuanto son maravillosas, su nitidez por cuanto es rara, su desarrollo por cuanto es sorprendente y simple" (Celeyrette-Pietri, 1987, vol. III, p. 689).

Como demuestra el ejemplo de Valéry, si hay una posibilidad de que el arte juegue un papel precursor, será trabajando no solo con, sino contra los saberes de su tiempo, e igualmente posicionándose en la intersección de varias disciplinas, fuera de los caminos marcados por ellas. Esta es la razón por la que Valéry convirtió a Leonardo en su figura tutelar. Genio plástico y genio matemático a la vez, Leonardo "ha tejido miles de lazos puros" (Valéry, 1894/1964, p. 11) ${ }^{19}$ entre las ciencias y las artes. Su capacidad para vislumbrar las estructuras comunes a los objetos más dispares le permitió establecer aleaciones inéditas entre elementos provenientes de disciplinas distintas y llevar así a cabo la unión entre el saber y el hacer, entre el conocimiento y la creación. Ingenioso como buen ingeniero, supo redefinir los papeles y lugares de intervención del arte interesándose no por las obras, sino por la dinámica de su generación, objeto de una teoría general de la morfogénesis en la frontera entre la estética, la física y la biología. Por este motivo constituye un modelo para Valéry: si todo conocimiento de la forma empieza como un conocimiento de lo viviente, entonces es necesario restablecer la continuidad de las operaciones intelectuales ejemplificada de forma magistral en su época por Leonardo.

\section{AGRADECIMIENTOS}

El original francés ha sido traducido al español por Borja Mozo. 


\section{NOTAS}

1. Edición española de Santos, C. (1993). El hombre y la concha. En Estudios filosóficos. Madrid: Visor, pp. 138-162.

2. La cita está en la página 139 en la edición española de Santos.

3. Página 140 en la edición española de Santos.

4. Páginas $139-140$ en la edición española de Santos.

5. Página 142 en la edición española de Santos.

6. Página 142 en la edición española de Santos.

7. Páginas 153-154 en la edición española de Santos.

8. Página 145 en la edición española de Santos.

9. Página 153 en la edición española de Santos.

10. Página 15 en la edición española de Santos.

11. Página 158 en la edición española de Santos.

\section{BIBLIOGRAFÍA}

Benveniste, E. (1951/1966). La notion de rythme dans son expression linguistique. En: Problèmes de linguistique générale (tome 1). Paris: Gallimard, pp. 327-355.

Boutot, A. (1993). L'invention des formes: chaos, catastrophes, fractales, structures dissipatives, attracteurs étranges. Paris: Odile Jacob.

Celeyrette-Pietri, N. (ed.) (1987-). Paul Valéry. Cahiers. Paris: Gallimard.

Chédin, O. (1982). Sur l'esthétique de Kant et la théorie critique de la représentation. Paris: Vrin.

Class, N. (2011). De l'usage du canon esthétique dans les sciences naturelles chez Goethe et de ses présupposés philosophiques. En: Lequan, M. (ed.). Goethe et la Naturphilosophie. Paris: Klinscksieck, pp. 33-61.

Cohn, D. (1999). La lyre d'Orphée. Goethe et l'esthétique. Paris: Gallimard.

Coquet, J.- C. (2006). Paul Valéry: la force et la forme. De la physique à la biologie et, ce faisant, à l'esthétique. Théorie Littérature Enseignement, 24, pp. 15-21.
12. Página 158 en la edición española de Santos.

13. Cabe recordar que en la época de Valéry el ADN todavía no había sido descubierto, que no se conocían ni la patología molecular ni las manipulaciones genéticas.

14. Edición española de Sánchez Robayna, A. (2007). Paul Valéry. Cuadernos (18941945) (Selección). Barcelona: Galaxia Gutenberg. La traducción es de Privat, M., Sainsz, F. y Sánchez Robayna, A. El fragmento citado se encuentra en las páginas 303-304.

15. Thom advierte igualmente una anticipación de la sensibilidad a las condiciones iniciales al observar Valéry que las mismas causas no producen nunca los mismos efectos, sino únicamente "efectos" más o menos semejantes.

16. Esa forma de pintar es lo más cercano a lo que también Deleuze denomina modulación (por oposición a la similitud), la única manera que, desde su punto de vista, es apta para hacernos

Deleuze, G. (1981). Bacon. Logique de la sensation. Paris: Éditions de la Différence.

Eynde, L. van. (2011). En quoi la Naturphilosophie est-elle proprement philosophique? En: Lequan, M. (ed.). Goethe et la Naturphilosophie. Paris: Klinscksieck, pp. 127-146.

Fagot-Largeault, A. (1995). Le vivant. En: Kambouchner, D. (ed.). Notions de Philosophie I. Paris: Gallimard, pp. 231-300.

Hytier, J. (ed.) (1957). Paul Valéry. CEuvres 1. Paris: Gallimard.

Jallat, J. (1982). Introduction aux figures valéryennes - Imaginaire et théorie. Pisa: Pacini.

Kellert, S. H. (1993). In the wake of chaos. Unpredictable order in dynamical systems. University of Chicago Press. https://doi.org/10.7208/chicago/9780226429823.001.0001

Petitot, J. (2003). Morphologie et esthétique. Paris: Maisonneuve et Larose.

Pietra, R. (1981). Valéry - Directions spatiales et parcours verbal. Paris: Minard. comprender la naturaleza del lenguaje analógico o del diagrama. La "modulación", cuya fórmula técnica es una "ley de analogía", actúa como "un molde variable continuo, que no se opone simplemente al modelado en claroscuro sino que inventa un nuevo modelado mediante el color" (Deleuze, 1981, p. 120). Y Deleuze añade: “El diagrama, agente del lenguaje analógico, no actúa como un código, sino como un modulador" (Deleuze, 1981, p. 113 [Traducción española de Herrera, I. (2002). Francis Bacon. Lógica de la sensación. Madrid: Arena Libros. La cita se encuentra en la página 121]).

17. Edición española de Castejón, E. y Conte, R. (1987). Introducción al método de Leonardo da Vinci. En Escritos sobre Leonardo da Vinci. Madrid: Visor. La cita se encuentra en las páginas 38-39.

18. Página 37 en la edición española de Castejón y Conte.

19. Página 16 en la edición española.

Prigogine, I. (1983). L'actualité de la conception du temps chez Paul Valéry. En: Robinson-Valéry, J. (ed.). Fonctions de l'esprit. Treize savants redécouvrent Valéry. Paris: Hermann, pp. 254-270.

Robinson-Valéry, J. (ed.) (1973). Paul Valéry. Cahiers 1. Paris: Gallimard.

Robinson-Valéry, J. (ed.) (1974). Paul Valéry. Cahiers 2. Paris: Gallimard.

Thom, R. (1983). La modélisation des processus mentaux: le 'Système' valéryen vu par un théoricien des catastrophes. En: Robinson-Valéry, J. (ed.). Fonctions de l'esprit. Treize savants redécouvrent Valéry. Paris: Hermann, pp. 193-206.

Valéry, P. (1894/1964). Introduction à la méthode de Léonard de Vinci. Paris: Gallimard.

Vercruysse, Th. (2011). La cartographie poétique: Tracés, diagrammes, formes (Valéry, Mallarmé, Artaud, Michaux, Segalen, Bataille) [Tesis doctoral inédita]. Université de Clermont-Ferrand: Ginebra.

Wunenburger, J.-J. (2011). Goethe, notes sur une épistémologie alternative. En: Lequan, M. (ed.). Goethe et la Naturphilosophie. Paris: Klinscksieck, pp. 25-42. 